\title{
A multi-level perspective of transition to circular economy with particular reference to a community renewable energy niche
}

\author{
Jack Finn*, Jack Barrie**, Elsa João* and Girma Zawdie* \\ (*University of Strathclyde, Glasgow, UK: **Zero Waste Scotland)
}

\begin{abstract}
This paper is an attempt to look into the processes involved in achieving full system transition to circular economy through the development of niche activities. Based on a case study relating to a community renewable energy niche, the paper argues that for transition to take hold and make progress, the socio-technical regimes underpinning the system of a linear economy would need to be disrupted through the agency of niches that bring forth radical innovations across a spectrum of activities. This argument is explored through a case study from the energy sector in Scotland. A Delphi study is conducted to assess the success of the Scottish Government in progressing community renewable energy (CRE) as a niche aimed at disrupting the incumbent fossil-based energy regime. The study finds that despite the commitment of the Scottish Government to empower, nurture and shield $\mathrm{CRE}$ as a niche, there is no clear evidence as yet to show whether these actions have achieved their desired effect of enabling the CRE niche to play a disruptive role. The paper also underscores the need for methodological refinement to enhance the robustness of the data used in the evaluation of policy efforts in niche development as a strategy for transition to circular economy.
\end{abstract}

Key words: Circular economy transition; niche innovation; community renewable energy systems; Delphi method; Scotland

\section{Introduction}

The ascendancy of 'consumerism' in contemporary society has placed Planet Earth in a precarious position, as evidenced by the fact that the pressure on resources to meet consumption and investment demand has already outstripped the planet's carrying capacity by well over 50 per cent (Jovane et al, 2017). Biodiversity loss, severe resource depletion and water, air and soil pollution all continue to jeopardise the earth's life support systems (Michelini et al, 2017; Geissdoerfer et al, 2017). A growing population will only continue to exacerbate these problems. In 2009, Rockström et al (2009) identified nine planetary boundaries which, if 
crossed, could lead to catastrophic changes on global environment. ${ }^{1}$ These boundaries represent a tipping point for humanity (Biermann, 2012), as breaching them would kick into action a series of feedback loops that cause unstoppable and irreparable changes, potentially rendering large parts of the planet uninhabitable. According to Steffen et al. (2015), humanity has already breached four of these planetary boundaries. These unprecedented challenges call for transition to a new production and consumption system that is consistent with the imperatives of sustainable development (Gooyert et al, 2016).

Given the desirability of transition to circular economy as an object of policy, the aim of this paper is to evaluate a country's progress in achieving transition to circular economy using the Delphi method. This is considered with reference to the experience of community renewable energy (CRE) as an area of niche innovation aimed at disrupting the fossil fuel-based energy regime in Scotland. The method combines the multi-level perspective, a heuristic which is widely adopted in the transitions literature, with the concept of system leverage points developed by Donella Meadows (1999). Such a method shows how far a country has come towards achieving a transition and what needs to be done to complete the process. It also shows why the actions taken by governments are failing to achieve system changes. This would allow policy makers to reflexively assess their progress and alter the course of actions, if needed.

The remainder of this paper is in six parts. In the second part following this introduction, the literature on the perspectives and dynamics of transition to circular economy is discussed from the vantage point of niche development as a strategy for disrupting incumbent technology regimes. The third part addresses the case of transition initiatives in Scotland with reference to the development of community renewable energy as a niche that is expected to evolve on a circular economy trajectory. The methodology of the study, which draws on the Delphi approach, is discussed in part four. Analysis of the survey data and the findings thereof are presented in part five. This is followed in part six by discussion of the findings, and recommendations for future research. Part seven presents the conclusions.

\section{Perspectives of transition to circular economy}

This section sets the context to the issue raised in the paper by providing a brief overview of the circular economy concept and the limitations in evaluating system changes. Subsequently,

\footnotetext{
${ }^{1}$ The nine identified planetary boundaries are: stratospheric ozone depletion, loss of biosphere integrity, chemical pollution, climate change, ocean acidification, freshwater consumption, land system change, atmospheric aerosol loading and nitrogen and phosphorus flows to the biosphere and oceans
} 
it discusses the methodological merit of combining the multi-level perspective and system leverage points to form a circular economy progress assessment tool for researchers and practitioners alike.

The circular economy (CE) model represents a radical departure from the traditional 'takemake-use-dispose' linear model currently in use throughout the global economy (Whicher et al, 2018; Lieder and Rashid, 2016). The fundamental goal of CE is to create closed loops of material flow throughout the entire economic system, effectively eliminating waste (Geng and Doberstein, 2008; Stahel, 2010; Krarup et al, 2015; Sauvé et al, 2016). As such, CE is most popularly defined as "an industrial economy that is restorative or regenerative by design" (Ellen MacArthur Foundation, 2013). It is also commonly associated with a shift of orientation of business models from 'consumer' to 'user' culture (Michelini et al, 2017; Urbinati et al, 2017), and a shift in favour of renewable energy through the development of niche innovation (Lazarevic and Valve, 2017).

\subsection{The multi-level perspective: A framework for conceptualizing system change}

Transitions from one system to another are hard to achieve (Lachman, 2013) because existing systems are stabilized by lock-in mechanisms (Walrave et al, 2017), such as sunk investments, powerful vested interests, regulatory mechanisms and established behavioral patterns (Geels, 2010). Systemic transformation calls for significant changes across an entire system, including, inter alia, technology regimes, user practices, markets, business models, policy orientation, infrastructure provision and cultural values (Geels et al, 2016).

System transitions occur when there is a disruption that results in a new structure (Lawhon and Murphy, 2011). The multi-level perspective (MLP) is a framework for understanding these transitions. It provides an overall view of the multidimensional complexity in socio-technical systems (Geels, 2010). The MLP views transitions as the coevolution of three nested levels that are referred to in the literature as niches, socio-technical regimes and landscapes. A sociotechnical regime is a coherent and stable meso level structure characterised by established technologies, user practices, knowledge, norms, and regulations (Markand and Truffer, 2008). Existing regimes can prove formidable barriers to transition, resisting, delaying or even derailing changes deriving from niche areas (Geels, 2018). Niches are the locus of radical innovations, often occurring in protected spaces where new technologies and innovations can grow, protected from regime pressures (Van Bree et al, 2010). The landscape consists of 
macro-economic and macro-political policy trends relating to economic, social and environmental issues of global significance (Doci et al, 2015; Kivama and Kern, 2016).

Transitions (or shifts in socio-technical regimes) occur as a result of top-down landscape pressures, such as the need to reduce $\mathrm{CO}_{2}$ emissions; and bottom-up development of niches and the emergence of disruptive innovation that destabilise the existing regime and bring forth systemic changes.

Hassink et al (2018) argue that MLP overemphasises structures and layers underpinning the modalities of innovation and technological change, thus giving too much weight to the views of corporate leaders and scientists, while doing little or nothing to address the role of micro players like consumers, workers and activists in the process. Despite this, MLP can help bring order and structure to the analysis of very complex, large-scale transformations in a system of the kind envisioned in sustainability transitions (Smith et al, 2010). This makes MLP particularly useful as a heuristic in the analysis of the dynamics of transition to circular economy. The following section shows how MLP can be used as a framework for applying system leverage points to evaluate progress of transition to circular economy.

\subsection{Leverage points in a system and their use in the context of MLP}

Incumbent socio-technical regimes act as barriers to system changes and niche innovation that would obliterate the lock-in and path dependent nature that defines their dominant position as vested interests. For systems change to happen, as in the case of transition to a circular economy, government policy plays a major role in helping niche players to overcome barriers arising from the dominance of incumbents (Geels, 2010, 2011, 2016). It is essential then that government policy targets the right places in the system to help niches to develop and achieve systemic change (Abson et al, 2016).

Meadows (1999) proposed a hierarchy of 12 intervention points for leveraging change in a system. These are conveniently grouped, as in this paper, into four categories, ranging from 'shallow' to 'deep' (see Table 1). 


\section{Leverage}

Points in

a system

Parameters The numbers that determine how the system operates, such as taxes and subsidies. This can also include changing the material stock of a system, such as rebuilding or constructing new infrastructure.

Feedbacks When trying to change a system to achieve a goal, receiving delayed information about the system state will result in poor planning and execution of policy. For example, a misaligned delay of information about electricity demand will result in either under capacity or overcapacity. Intervening by introducing measures to improve the speed and clarity of information feedback can increase system change. Intervention here could also involve creating or strengthening a negative feedback loop, a mechanism designed to keep the system close to its desired state; just like a thermostat monitors and maintains a rooms temperature.

Intervention can also include driving and creating positive feedback loops. Positive feedback loops are self-reinforcing, the more they work the more they gain power to work. For example, the more money in your bank the more interest you earn.

Design Interventions at a design level target the rules of a system. These are the rules that define a systems scope and boundaries. This could also include changing who has power over the rules in a system. Design interventions could also help increase flexibility in a system by encouraging innovation, experimentation and self-evolution within the system.

Intent Intervening at the intent of a system means to change the overarching goals which drive it. Every leverage point above this on the list will conform to the goals of the system. For example, If the principal goal of the system is to achieve economic growth the entire system will conform to achieve this goal.

Finally, at the deepest possible level, an intervention can target change in the paradigm out of which a system arises. Paradigms are a societies deepest held set of beliefs about how the world works, and determines a systems goals, design, feedbacks and parameter.

The shallowest leverage points correspond to the 'parameters' and 'feedbacks' in a system; and the deepest to the 'design' and 'intent' of a system. According to Meadows (1999), these shallow leverage points are often targeted by policy makers and are least effective in inducing system change.

Although 'parameter' and 'feedback' level interventions often appear to have the potential to make very significant differences to system behaviour, they rarely do so since they do not intervene deep enough to achieve systemic change. But when shallow leverage point interventions are employed in combination with those at the deepest leverage points, namely 'design' and 'intent' levers, system change is likely to be achieved. While MLP helps policymakers to set out the broad contours of transition to circular economy, the leverage points 
in a system are useful for assessing progress of transition to circular economy as they enable us to quantify and track the leverage points an intervention is targeting. Progress toward a circular economy transition can only be said to be occurring if both deep and shallow leverage points are being targeted.

By employing a multi-level perspective, the linear economy can be thought of as a distinct system which is comprised of many different socio-technical regimes. At the landscape level, pressures, such as climate change, are pushing down on the current linear system creating the impetus for change. At the niche level are innovations which have the potential to destabilise and alter the existing linear regimes. At the meso level, the socio-technical regimes can be thought of as mini-systems, all containing different combinations of technology, user practices, knowledge and norms which are currently aligned with linear economy principles.

To achieve transition to a circular economy, each regime would need to be destabilised and transformed by the evolution of multiple CE-orientated niches. These are niches which contain technology, user practices, knowledge and norms that are in line with the principles underlying the $\mathrm{CE}$ system. The result of these individual regime transformations would be a transition to a CE system where all the socio-technical regimes in the system are aligned with the underlying CE principles.

As has already been established, government policy acts as the principal driving force behind nche progress during transition to a CE. Therefore, assessing the extent to which government intervention is helpful for a niche to overcome regime barriers is the first step in measuring how much progress is made in achieving transition to $\mathrm{CE}$. By combining the assessments of progress made in individual CE-orientated niches, it is possible to gauge the total progress made in transforming a regime; and by looking at the progress in transforming each regime in the system, it should be possible to gauge the total progress made towards transforming the system.

The points of leverage in a system can provide suitable criteria for assessing the success of policy in progressing the development of circular economy orientated niches. System change would be expected to occur if interventions targeted the deeper 'design' and 'intent' leverage points as well as the shallower 'feedback' and 'parameter' levers. 


\section{Scotland as a case study for circular economy transition}

This paper focuses on the case of Scottish transition to circular economy for the following reasons. In 2016, the Scottish Government published a white paper entitled "Making Things Last - A Circular Economy Strategy for Scotland”, which outlined a commitment to transform four sectors, including food and drink, remanufacturing, construction and energy infrastructure. It also recognised the need to facilitate societal change and the key roles to be played in both the private and public sectors. In 2017, at the World Economic Forum annual meeting in Davos, the Scottish Government received the "award for circular economy governments, cities and regions" in recognition of their commitment to circular economy transition and their global leadership in promoting circular economy-orientated niches.

The choice of the energy regime for investigation in this paper is predicated on the ground that its transformation is commonly identified as a crucial factor in the course of transition to circular economy (Lazarevic and Valve, 2017) and the recognition by the Scottish Government of community renewable energy (CRE) as a niche prioritised for development under a 'protected space' arrangement.

Scotland's current energy regime involves a centralised energy generation system powered by fossil fuels. About $60 \%$ of total annual electricity output is generated from non-renewable sources which are fossil fuel- and nuclear energy-based (Scottish Government, 2017). A characteristic feature of the energy sector in Scotland is that electricity and gas distribution is highly centralised (Hunt and Milne, 2013). In terms of heat generation, the plan is to have $11 \%$ of the energy consumed for generating heat to be provided by renewable sources, leaving the lion's share for non-renewable energy resources (Scottish Parliament, 2017). The challenge for policy is to shift the energy regime from the current fossil fuel trajectory to renewable trajectory to facilitate transition to circular economy.

\subsection{Community renewable energy (CRE)}

Nolden (2013) defines community renewable energy (CRE) as the installation of electricity generating technologies in communities which have part or full ownership of municipal utilities or communities benefitting from co-ownership, business taxes and community funds. There is a general consensus that for a project to be considered CRE, it must include shared or full 
ownership by some form of institution which represents the interests of the local communities (Van-Veelen, 2017).

CRE schemes offer a range of social and economic benefits in addition to the obvious environmental benefits of renewable energy (Haf et al, 2018). A fundamental underpinning of CRE is public participation in decision making on project development. This adds to the social sustainability attribute of CREs (Murphy, 2012). Viardot (2016) also shows that part ownership of local communities in CRE schemes can help lower traditional barriers to renewable energy implementation through commitment to the generation of benefits, such as the lowering of local energy prices and financial gains from the investment.

In addition, CRE development also provides a significant boost to the regional value-added chain of the community ( $\mathrm{Li}$ et al, 2016). The capital generated from the project can be reinvested into the community, boosting the local and regional economies. The local and regional economies can also experience a boost from the creation of new jobs and the possibility of levying business taxes on the companies who operate production plants/sites.

By 2016, there were 167 CRE projects completed or in development in Scotland (Local Energy Scotland, 2016). The total installed capacity for locally and community owned energy was 666MW. However, only $81 \mathrm{MW}$ of this was owned by community groups (Energy Savings Trust, 2017). The Scottish Government have set targets of $1 \mathrm{GW}$ production by 2020 and 2GW by 2030 for locally and community-owned renewable energy projects; and there is policy commitment for $50 \%$ of the proposed renewable projects to be of shared ownership type by 2020 (Scottish Government Energy Strategy, 2017).

Policy commitment to the development of CREs in Scotland is predicated on the belief that the CRE niche is circular economy-orientated in its nature by virtue of the social, economic and environmental benefits deriving from CREs, which in combination with the importance of renewable energy transition for the CE, would firmly establish CREs as a CE-orientated niche. This paper seeks to determine the extent of success of the Scottish Government in progressing the development of the CRE niche.

\section{Methodology}

This section addresses the Delphi method, which is used to evaluate progress of the community renewable energy (CRE) niche in Scotland along the circular economy trajectory. There are many issues and restrictive conditions that bear on policy regarding transition to circular economy 
and the development of renewable energy systems. These include, inter alia, the Scottish devolution settlement, EU and UN policies, and the issue of Brexit. However, these issues fall outside the scope of this paper. The focus here is solely on the actions the Scottish Government have already taken without consideration of the constraints deriving from sources beyond the level of devolved government.

\subsection{The Delphi method and its suitability for system transition research}

The Delphi method, which was created in the 1950s by the US RAND Corporation (Nowack et al, 2011), is used to elicit expert opinion on a given subject (Hasson and Keeney, 2011). It achieves this by using a written survey technique to facilitate an efficient group dynamic process between expert participants in a virtual panel known as 'Delphi panel' (Von der Gracht, 2012).

There are three fundamental characteristics which are generally present in all Delphi studies. First, participation in the panel is anonymous. Anonymity has significant advantages, such as leading to higher response rates and removing the persuasive effects a dominant personality may have in a group setting (Pill, 1970; Strauss and Zeigler, 1975). The second common characteristic is iteration, with more than one round used for eliciting expert views on issues. Round one usually provides a forum for idea generation. In round two, the experts are asked to critique all the ideas generated in round one against a set of criteria. In round three, the experts receive the results of round two (i.e. the views of other experts) and are asked to examine their own assessments and make changes if they wish. The third common characteristic is controlled feedback by a moderator.

Consensus building among experts is considered crucial in Delphi exercises (Von der Gach, 2012). The Delphi method is particularly useful in areas of limited research and where a lack of clarity exists (Iqbal and Pipin-Young, 2009) because it uses expert knowledge in the subject area to help determine conclusions. The underlyng point is that consensus of expert opinion on a forecast is much more likely to prove accurate (Loe, 1995). As a result, the Delphi method has become a consolidated tool for forecasting studies in scientific areas (Gallego and Bueno, 2014). This collection of traits makes the Delphi method well suited to the study of sustainability and circular economy transition because these are issues subject to diverse and contested opinions, and with no historical comparisons used as points of reference. 


\subsection{Designing the Delphi study}

For the purpose of this research, CRE is defined as 'renewable energy schemes in which communities have a financial stake and actively participate in the process of project development.' This definition ensures that only shared ownership models are considered, as shared ownership is a prerequisite for achieving the social benefits deriving from the implementation of CRE projects. Experts are trusted for their abilities to thoroughly understand CRE projects, the extent of the benefits CREs produce for local communities and the role they play in the course of sustainability transitions.

Given that experts could tick more than one box during the assessment phase, there is a potential for experts to have multiple differences of opinion on the same issues. This would make it difficult to achieve consensus among all experts for every issue after just one round of consultation. When, for example, three out of five experts agree after a number of rounds, consensus is considered to have been reached by 'majority rule'. When four out of the five agree, it is considered a 'near unanimous consensus'; and when all five agree, a 'unanimous consensus' is achieved. The underlying assumption of the Delphi exercise is that expert views on issues are normally distributed and that repeated rounds of consultation would, rationally enough, diminish the standard deviation of the spread of views leading to near-unanimous or unanimous consensus.

\subsubsection{Deciding on the number of rounds used in the study}

Gallego and Bueno (2014) suggest that two or three assessment rounds could be considered optimal in a Delphi study. With more than three rounds, it is argued experts could abandon the project due to 'consultation fatigue', or else simply move towards a consensus position not out of conviction but out of the desire to bring what would be a long drawn out process to a close. The problem is acute where there is no generous financial incentive to the Delphi experts, as in the case of this research. Therefore, a three-round Delphi was selected (see Figure 1).

The first round had the panel of experts pointing out what they felt to be the most important "actions" taken by the Scottish Government in the 'last five years' to progress development in the CRE niche. A period of five years was deemed suitable as a medium-term period on which to base the study. It was considered neither too short to cut out any older but potentially vital actions, nor too long for the experts to have a potentially prohibitive range of actions to choose from. From the actions generated in round one, five would be chosen for assessment in the next round. The second round would have the experts performing an assessment on the five chosen 
actions; and the third round would be used to give the experts an opportunity to view the results of the other panellists and for the panel coordinator to determine whether there is any tendency towards a consensus.

\section{Stages of the Delphi Method}

\section{Expert Panel's task}

\section{Reaserchers task}

Round One - Suggest most important actions taken by Scottish Government to promote Community Renewable Energy

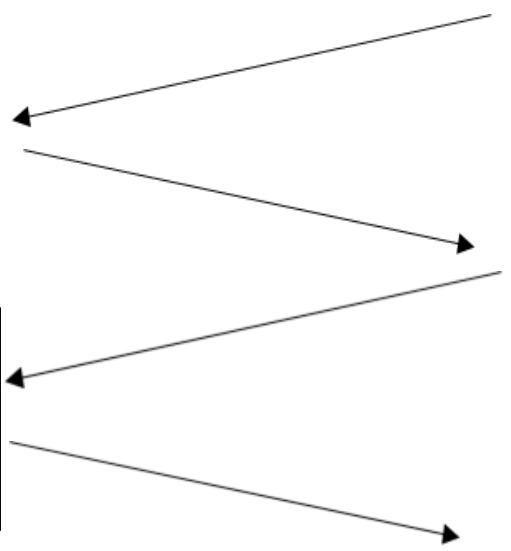

Recruit panel of experts to participate in the study

Evaluate suggested actions from experts and select five to be assessed in round two

Round Two - Complete an assessment of five actions using "the points of leverage in a system" as an assessment tool

Round Three - Read assessment of other experts and, if necessary, decide whether to change your own assessment to reach a consensus

Figure 1 - The stages of the Delphi study used in this research to assess the effectiveness of the Scottish Government's interventions to progress the niche of community renewable energy.

\subsubsection{Recruiting a panel of experts to participate in the Delphi panel}

The next step was to identify and recruit a panel of experts. Experts were sought from the public, private and third sectors, as well as from academia. These sectors are involved directly in the development of CRE projects and have first-hand experience in the ways government actions are affecting CRE development. Academics who specialise in CRE have expertise which is distinct from industry professionals, yet no less important when considering how best to develop niche innovations (Etzkowitz, 2003).

The number of participants for a Delphi study does not necessarily need to be high, as there is no evidence of strong correlation between the number of experts and the quality of the 
conclusions that are reached by the group (Ocampo et al, 2018; Rowe and Wright, 2011). It is also important to refrain from recruiting less experienced experts to reach a predefined goal as this would weaken the robustness of the results. This is a particularly important point for this research, since "compared to other areas of the renewable energy market in Scotland, there are relatively few people working in the CRE sector at this time" (Hannah Smith, Senior Policy Advisor, Scottish Renewables, Pers. Comm., $3^{\text {rd }}$ August 2018). In addition, the study lacked the financial resources to compensate experts for their participation. This has the potential effect of limiting the willingness of experts to participate in the Delphi panel, particularly if this involves several rounds of consultation. Consequently, it was decided to recruit a panel of five experts drawn from across all four desired sectors (see Table 2).

Potential expert panellists were identified via online searches and were then asked to participate through email. Participation of the private sector expert was confirmed only after the completion of round one, which means that only four experts participated in round one (idea generation). This reduced the number of actions that were recommended but did not have any impact on the validity of the results of the study as the private sector expert was still able to assess each action chosen and reach a consensus with the other experts.

Table 2 - A description of the five experts who agreed to participate in the Delphi study designed to assess community renewable energy progress in Scotland.

\begin{tabular}{ll}
\hline Expert & Description \\
\hline Third sector expert & $\begin{array}{l}\text { Employed as a senior member of a not-for-profit company whose aim is to } \\
\text { promote renewable energy uptake in Scotland. The expert has several years' } \\
\text { experience in helping to promote community renewable energy. }\end{array}$ \\
Public Sector Expert & $\begin{array}{l}\text { Employed within the public sector for two years, focusing on implementing } \\
\text { circular economy initiatives within the Scottish energy sector including } \\
\text { working with communities to implement energy solutions. }\end{array}$ \\
Private Sector & $\begin{array}{l}\text { Has spent four years employed at a private firm which works with } \\
\text { community groups to develop community renewable energy plans and } \\
\text { projects. }\end{array}$ \\
Academic Expert (1) & $\begin{array}{l}\text { Teaching academic employed at a university in Scotland with an extensive } \\
\text { history of research in community renewable energy. This includes co- } \\
\text { authoring four articles published in professional academic journals, all of } \\
\text { which concerned community renewable energy in Scotland. }\end{array}$ \\
Academic expert (2) & $\begin{array}{l}\text { Teaching academic employed at a university in England with an extensive } \\
\text { history of research in community renewable energy. This includes authoring } \\
\text { or co-authoring four articles published in professional academic journals, } \\
\text { two of which concerned community renewable energy in Scotland. }\end{array}$ \\
\hline
\end{tabular}




\subsubsection{Assessment criteria to be used for the study}

The "points of leverage in a system" (Meadows 1999) were used as assessment criteria in this study. Experts were asked to evaluate the Scottish Government actions included in the assessment and determine the leverage point which each action targeted in the system to try and promote CRE niche progression.

\subsection{Executing the Delphi}

\subsubsection{First round}

The first round of the Delphi generated 14 actions in total, five of which were subsequently chosen by the Delphi moderator to be put into a questionnaire in the second round (see Table 2). The five actions were chosen based on whether they had been recommended by two or more experts. This was a strength of the Delphi method; the actions which were to be reviewed by the panel in round two were generated by the experts themselves. This helped to remove to some extent the potential for bias of the Delphi moderator during the selection of actions to be featured in round two. That these actions were generated by experts in the field of CRE makes it more likely that they are in fact among the most important actions taken by the Scottish Government and thus strengthens the validity of the exercise.

\subsubsection{Second round}

At the commencement of the second round, the five panellists were sent a questionnaire containing a description of the five actions which were to be assessed against the four leverage points noted above. The five action points include: the 2017 Energy Strategy; the 2015 Community Empowerment Act; the establishment of Local Energy Scotland; the Community and Renewble Energy Scheme (CARES); and the political narrative that establishes Scotland as leader in community energy and community empowermnt (see Table 4). Each action was described briefly, where possible retaining the original wording of the expert(s) who suggested it. Where necessary, the original wording was edited by the Delphi moderator to ensure that every panellist would recognise and understand the action described.

The questionnaire included a brief introduction to the concept of leverage points in a system, before giving a detailed explanation of the parameters, feedbacks, design and intent leverage points. It was decided that the assessment criteria would use only these four groups, as opposed to the 12 individual leverage points. The explanations of the four leverage points were taken 
directly from Meadows (1999) with some redaction to give a brief and clear description of the areas associated with the leverage points (see Table 1).

As Meadows (1999) notes, systems thinking is a complicated subject to understand, and the application of leverage points to real world situations is often unintuitive and difficult. Given the difficulty of the subject matter, the high level of commitment required to participate in any Delphi panel (Iqbal and Pipin-Young, 2009) and the associated high risk of dropping out of the panel, it was felt too much to ask experts to learn 12 individual leverage points and apply them appropriately. Indeed, it may have risked experts dropping out in the middle of the Delphi process. The decision was also made not to inform the panellists of the importance of government actions targeting the deeper leverage points as it was felt this may influence their decision making. It was not considered necessary for experts to be aware of this to understand the concept of leverage points or to be able to apply them in the assessment.

The experts were then asked to fill out an assessment table. Panellists could tick more than one box per action, because it is possible that a government action could target more than one leverage point. Panellists were also asked to leave a brief description explaining why they assessed each action as they did. This was for the benefit of the other experts who could read their justifications and decide, if necessary, whether they wanted to make an alteration to their own assessment. Although it is rare for Delphi panellists to include comments (Von Der Gach, 2012), it was allowed in this study because of the small number of participants. Each expert would only have to read the comments of four other panellists. The inclusion of comments added richness to this method and helped to facilitate an aspect of group discussion. Participants were able to see other experts' assessments and also their justifications and respond as they wished.

\subsubsection{Third round}

In the third stage of the method, each expert's assessment from the second round was returned to them along with the assessments of the other experts. If four experts had ticked one leverage point for a certain action, the expert who did not tick this box was alerted to this by highlighting this in red in the assessment tables of the other participants. All the comments made by the other panellists to justify their selections were also included. If three experts had ticked a certain leverage point for an action but the other two had not, they were alerted to this with yellow highlighting. The questionnaire also included text explaining specifically for each expert where they were not in agreement with the others. Each expert was then asked to read these 
explanations and decide whether they would like to alter their own assessments after having read the assessments and justifications of the other panellists. The decision was made not to specifically draw attention to situations where only one or two experts had ticked a leverage point for a certain action. This was because they did not have a 'majority consensus', and it was felt that to reach a 'proper consensus' on these judgements, additional rounds would have been necessary to facilitate a robust panel discussion.

\section{Analysis and results}

The results of the Delphi study show that there are signs of consensus among experts in Scottish CRE that significant progress has been made in the development of the CRE niche over the last five years. The Delphi experts were unanimous that the five most important actions taken by the Scottish Government had targeted the intent, design, feedback and parameter leverage points (see Table 3 ).

That the experts independently reached this consensus strongly suggests that the interventions made by the Scottish Government would enable the CRE niche to disrupt the fossil-based energy regime in Scotland. The CRE niche also has the potential to transform Scotland's sociotechnical energy regime in line with the principles of CE. However, as will be discussed below, the Delphi study was not able to show the full measure of progress made in the CRE niche, only that it is on the CE trajectory.

\begin{tabular}{|l|c|c|c|c|}
\hline & Parameter & Feedbacks & Design & Intent \\
\hline Action 1 - Energy Strategy & 2 & 1 & 2 & 5 \\
\hline Action 2 - Community Empowerment Act & 0 & 2 & 0 & 3 \\
\hline Action 3 - Establishing LES & 0 & 4 & 3 & 1 \\
\hline Action 4 - CARES & 5 & 1 & 2 & 0 \\
\hline Action 5 - Political narrative & 0 & 0 & 0 & 5 \\
\hline
\end{tabular}

\section{Key:}

Unanimous Consensus (5/5)

Near Unanimous Consensus (4/5)

Majority Consensus (3/5)

No Consensus

Table 3 - Results of the Delphi study showing a large degree of consensus among experts that Scottish Government interventions targeted all four leverage points. This means CRE in Scotland is on the right trajectory toward disrupting the existing energy regime in Scotland and contributing toward systemic change. 


\subsection{Results of the first stage of the Delphi method}

During the first stage, the Delphi panellists made their suggestions concerning the most important actions the Scottish Government took to promote CRE. A list of five actions were subsequently chosen to prompt reactions by the Delphi experts (see Table 4).

Table 4 - Description of the actions (as given by the expert panellists) chosen to be assessed in round two

\section{Scottish Government Description as given by experts \\ Actions Selected for \\ Assessment in round two of \\ Delphi}

\begin{tabular}{ll}
\hline Action 1. The 2017 Energy & The publication of the Scottish government's energy strategy in \\
Strategy & $\begin{array}{l}\text { 2017, which established a commitment to developing } \\
\text { community renewable energy as well as establishing targets of }\end{array}$ \\
[Recommended by 4 experts] & GW of community and locally-owned renewable energy by \\
& 2020 and 2 GW by 2030.
\end{tabular}

Action 2. The Community Empowerment Act 2015

[Recommended by 2 experts]

The Community Empowerment Act of 2015 which expanded the right to buy land $\&$ buildings for communities and helps facilitate the transfer of local authority buildings to communities.

Action 3. Establishing Local Energy Scotland (established in 2013)

The establishment of Local Energy Scotland, a government agency created to promote and support the uptake of community renewable energy.

[Recommended by 3 experts]

Action 4. CARES

[Recommended by 4 experts]

Action 5. Establishing a strong political narrative

[Recommended by 1 expert]
CARES (commenced in 2013) - The Community and Renewable Energy scheme, administered by Local Energy Scotland, provides loans to fund a range of different types of community renewable energy schemes.

Working hard to establish a strong political narrative that Scotland is a leader in community energy and community empowerment.

Actions 1-4 were selected on the basis that they were recommended by multiple experts. On the other hand, Action 5 was recommended by only one expert, but it was selected on grounds that there was evidence in the literature showing that deliberate efforts to create a narrative of leadership in renewable energy and citizen participation were beneficial to CRE uptake in Denmark and Germany (Doci and Gotchev, 2016; Hake et al, 2015; Rommel et al,2016).

Expert views are sought in the Delphi process to determine the significance of the actions taken by the Scottish Government in the last five years to promote transition to circular economy through niche development. Four of the five actions chosen for round two were suggested by 
two or more experts. Three were suggested by three or more. The fact that these actions were raised multiple times from such a small pool of experts serves to highlight their importance as critical actions.

\subsection{Results of the second stage of the Delphi}

This section details action-by-action the results of the second round of the Delphi process and the implications thereof. In this round, the experts were asked to view a list of five actions taken from suggestions in round one, and to assess them using the four points of leverage in a system selected for this study.

\subsubsection{Action 1 - The Scottish Government's 2017 energy strategy}

In the initial assessment, there was unanimous consensus that the energy strategy targeted the 'intent' leverage point (see Figure 2). In addition to 'intent', Academic (1) listed it as targeting all four leverage points, while Academic (2) listed it as a parameter intervention. The private sector expert agreed with Academic (1), listing it as 'design' and 'intent' intervention.

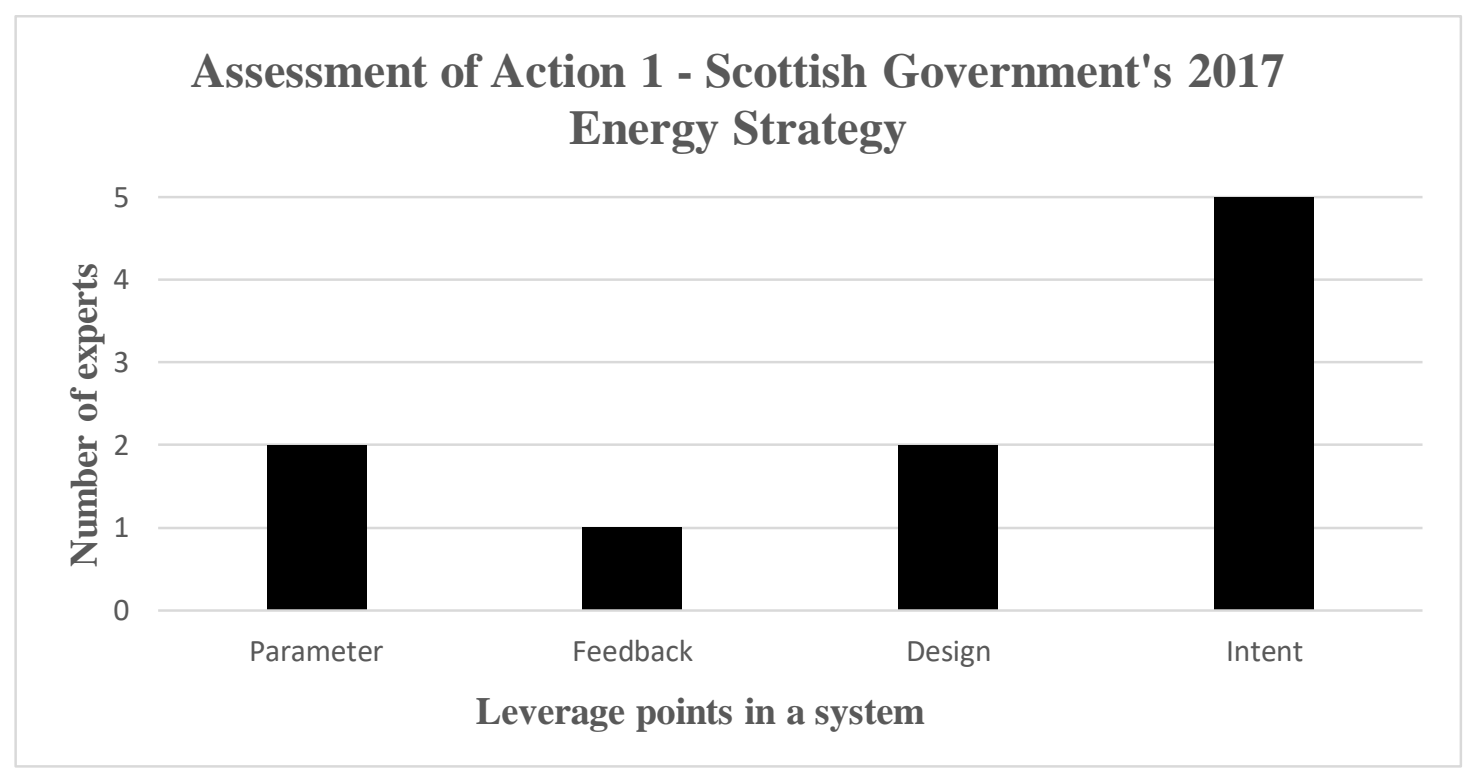

Figure 2 - Results of the expert assessment of action 1 - The Scottish Government's 2017 energy strategy

\subsubsection{Action 2 - The Community Empowerment Act (2015)}

After the second-round of assessments, there was a near unanimous consensus that Action 2 targeted the design leverage point (see Figure 3). Additionally, Academic (1), Academic (2) and the private sector expert had selected the 'intent' leverage point, creating a majority 
consensus. Academic (1) and the private sector expert also listed it as 'feedback' and 'intent' intervention.

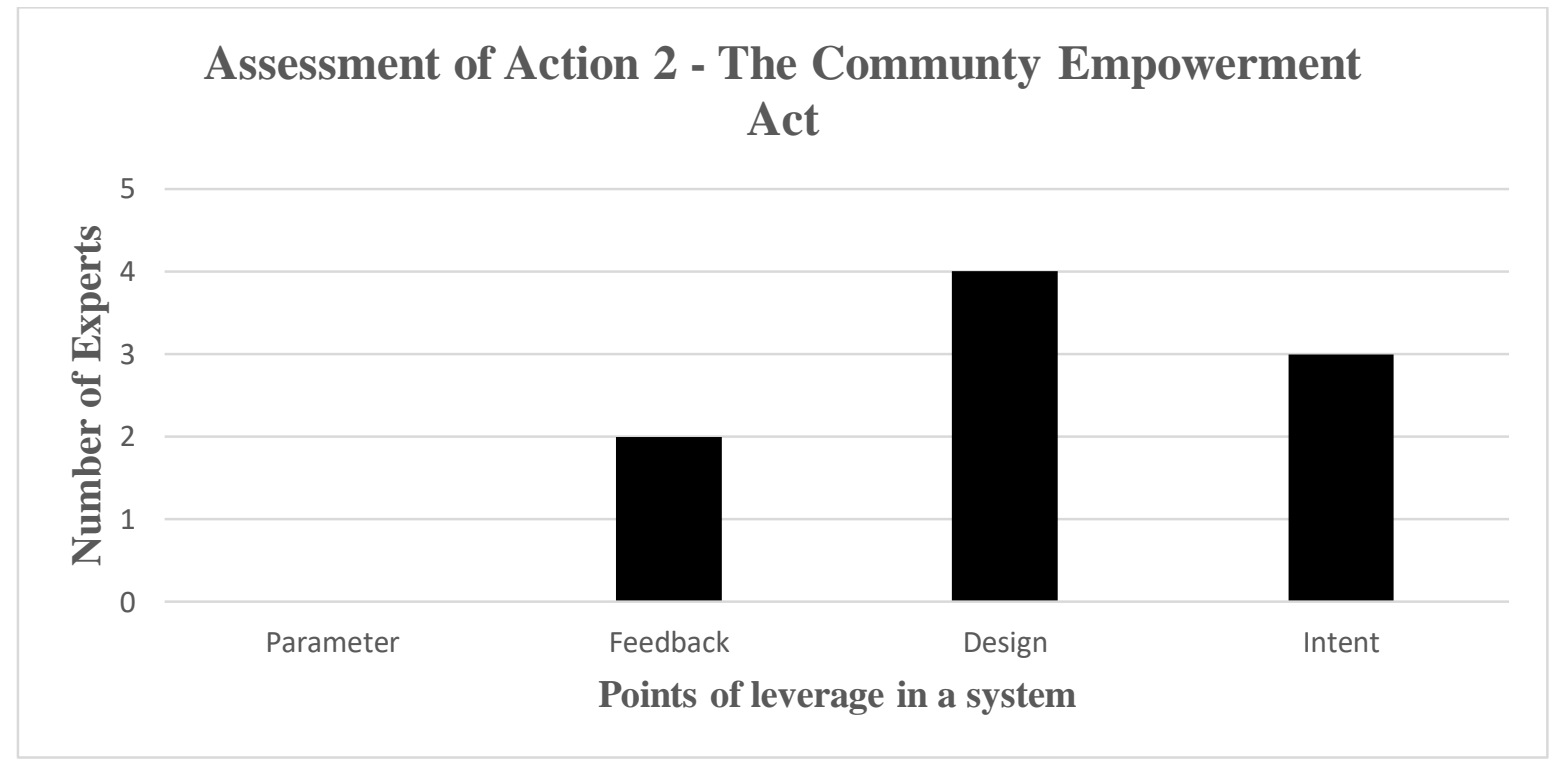

Figure 3 - Results of the expert assessment of Action 2 - The Community Empowerment Act (2015)

\subsubsection{Action 3 - The establishment of Local Energy Scotland}

After the assessment stage, all except Academic (2) considered the establishment of Local Energy Scotland to be 'feedback' intervention, while three considered it to be 'design' intervention (see Figure 4). The private sector expert also thought it was 'intent' and 'feedback' intervention. After two rounds, there was a near unanimous consensus that action 3 targeted the 'feedback' leverage point, and a majority consensus that it targeted the 'design' leverage point.

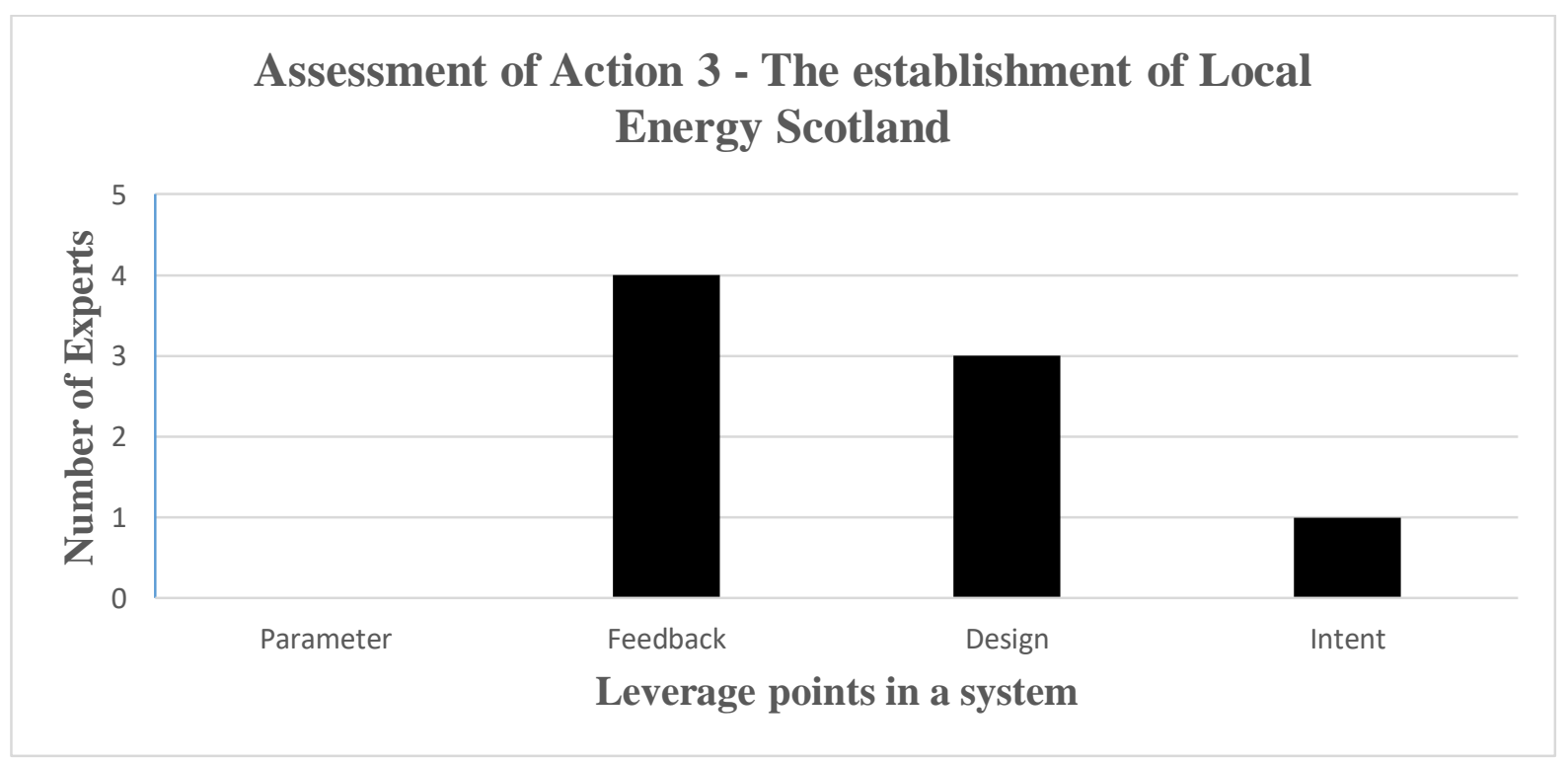




\subsubsection{Action 4 - The "Community and Renewable Energy Scheme" (CARES)}

At the end of the assessment in round two, all five experts were in unanimous agreement that CARES represented a 'parameter' intervention (see Figure 5). In addition, both academic experts felt it targeted the 'design' leverage point and, in the case of Academic (1), the 'feedback' leverage point as well.

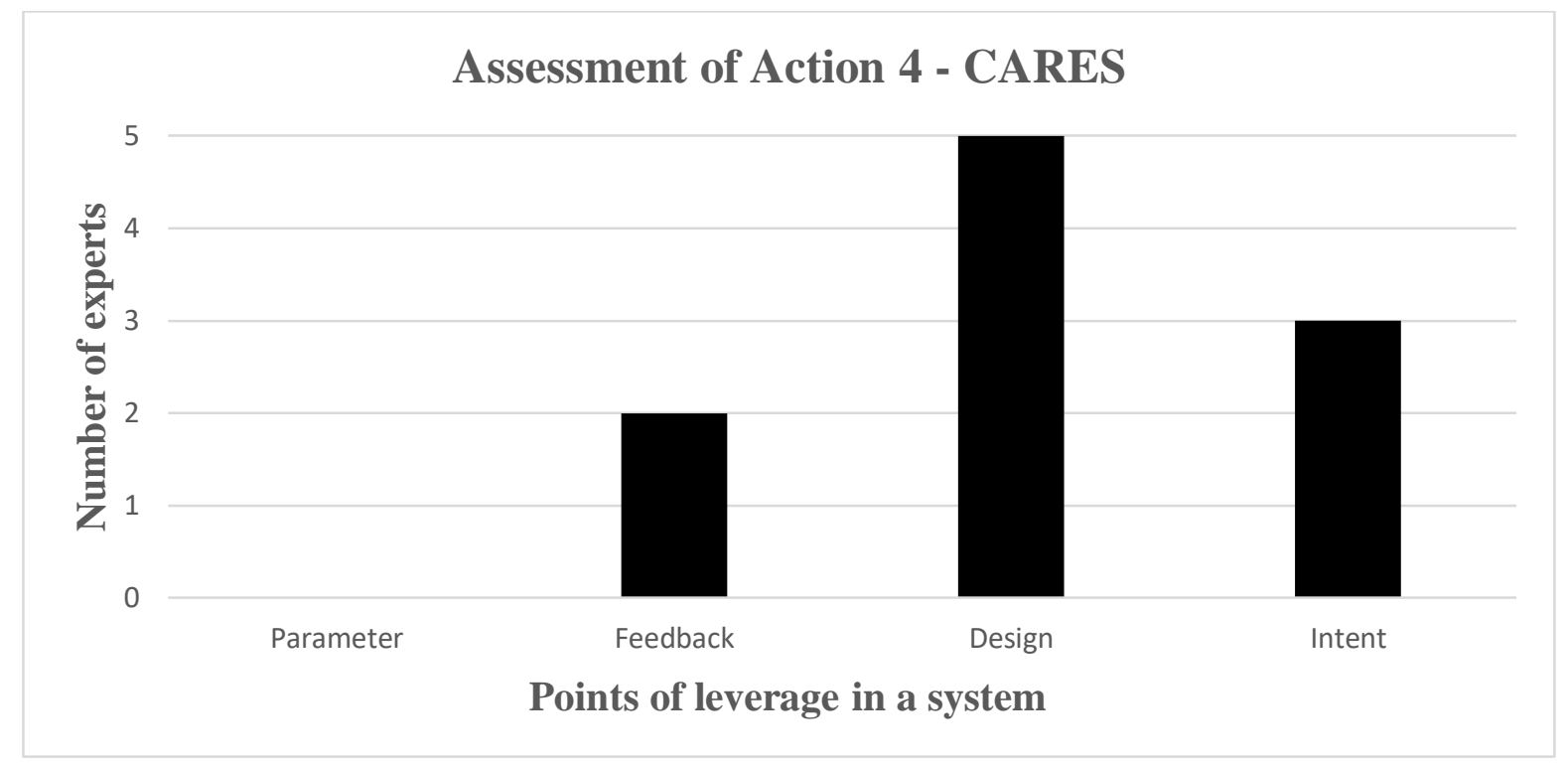

Figure 5 - Results of the expert assessment of Action 4 - the "Community and Renewable Energy Scheme" (CARES)

\subsubsection{Action 5 - Creating a strong political narrative that Scotland is a world leader in CRE}

Of all the actions assessed, Action 5 was the only action which was selected unanimously as targeting only one leverage point - i.e. 'intent' intervention (see Figure 6). 


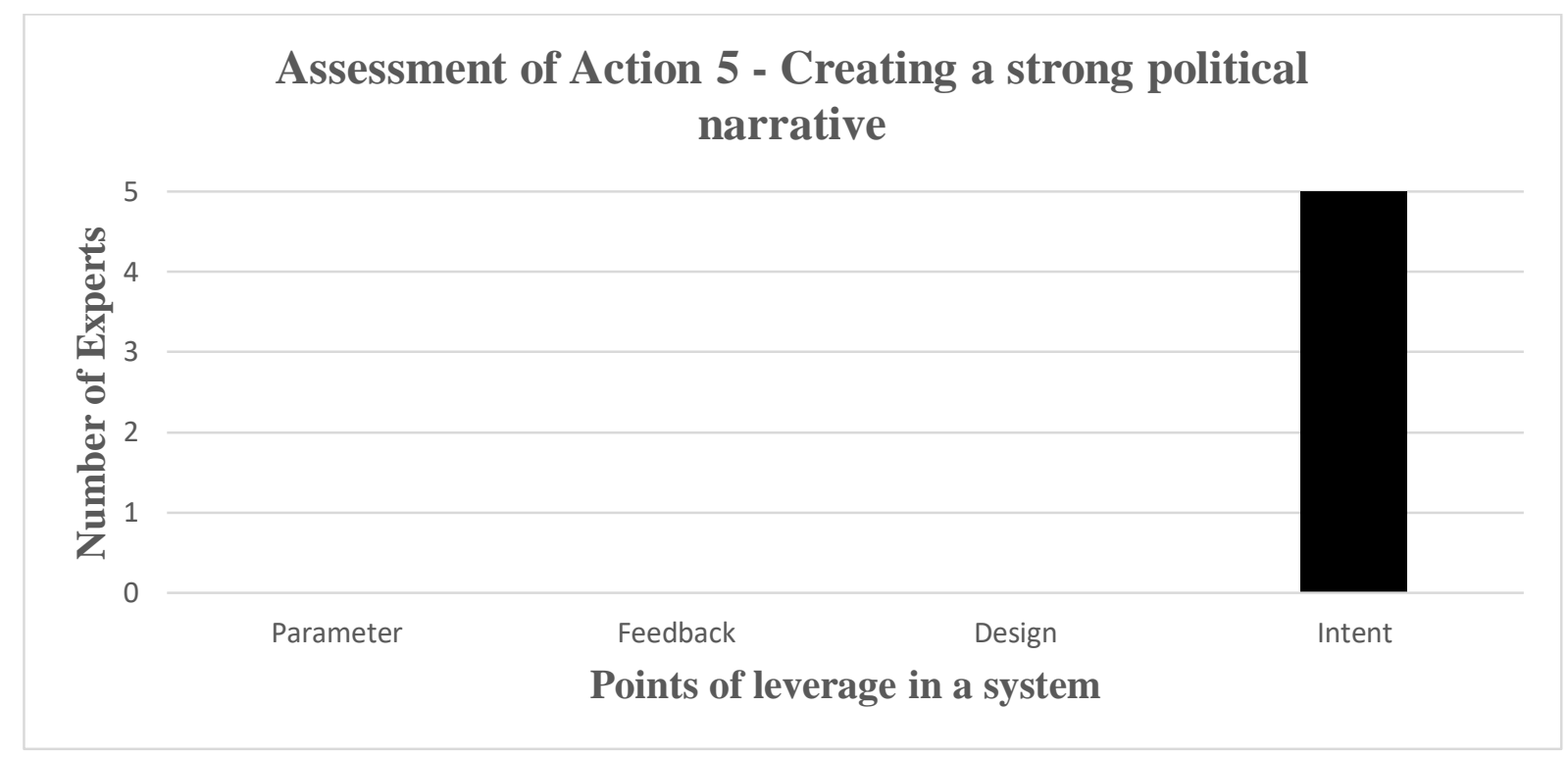

Figure 6 - Results of the expert assessment of Action 5 - Creating a strong political narrative that Scotland is a world leader in CRE. There was a unanimous consensus that action 5 targeted the "intent" leverage point.

\subsubsection{Analysis of the second stage of the Delphi exercise}

Before the experts had seen the responses of the other participants at the end of the secondround of assessments, there was a near unanimous consensus over every action regarding the leverage point it targeted. This effectively eliminates the possibility that experts altered their assessment purely to reach consensus. The level of consensus achieved independent of influence from others only adds to the weight of experts' forecast of the progress made in CRE on the CE trajectory.

It is also noteworthy that of the five actions assessed in stage two, just one was unanimously thought to target only one leverage point. The energy strategy was variously considered to target all four leverage points, while actions 2-4 were considered by various experts to target three leverage points.

\subsection{Results of the third stage of the Delphi}

This section details the results of the third round of the Delphi study. In this stage, experts were asked to read the assessments of the other experts and decide if they would like to alter their assessments to reach a consensus. This section will record these results and discuss the implications they have for the research method of this study. 


\subsubsection{Attempting to reach consensus}

Consensus was not sought on an assessment when only one or two experts had judged an action to target a certain leverage point. It was judged that only one consensus building round was not enough to allow time for group dialogue for the few to convince the many or vice versa. In contrast, when there was a majority consensus regarding an intervention, those who disagreed could be presented with three or more justifications from the other experts so that they could make up their mind on the matter without the need for more dialogue.

Consensus was therefore actively sought only for Action 2 (the Community Empowerment Act) and Action 3 (Local Energy Scotland) during round three of the Delphi process. After the second stage, all experts except Academic (2) marked Action 2 as intervening at the "design" leverage point (see Figure 3). After seeing the assessments of the other panellists during the third round of the study, Academic (2) decided to alter their assessment by including "design" as a targeted leverage point. This created a unanimous opinion among experts that Action 2 targeted the "design" leverage point (see Figure 7).

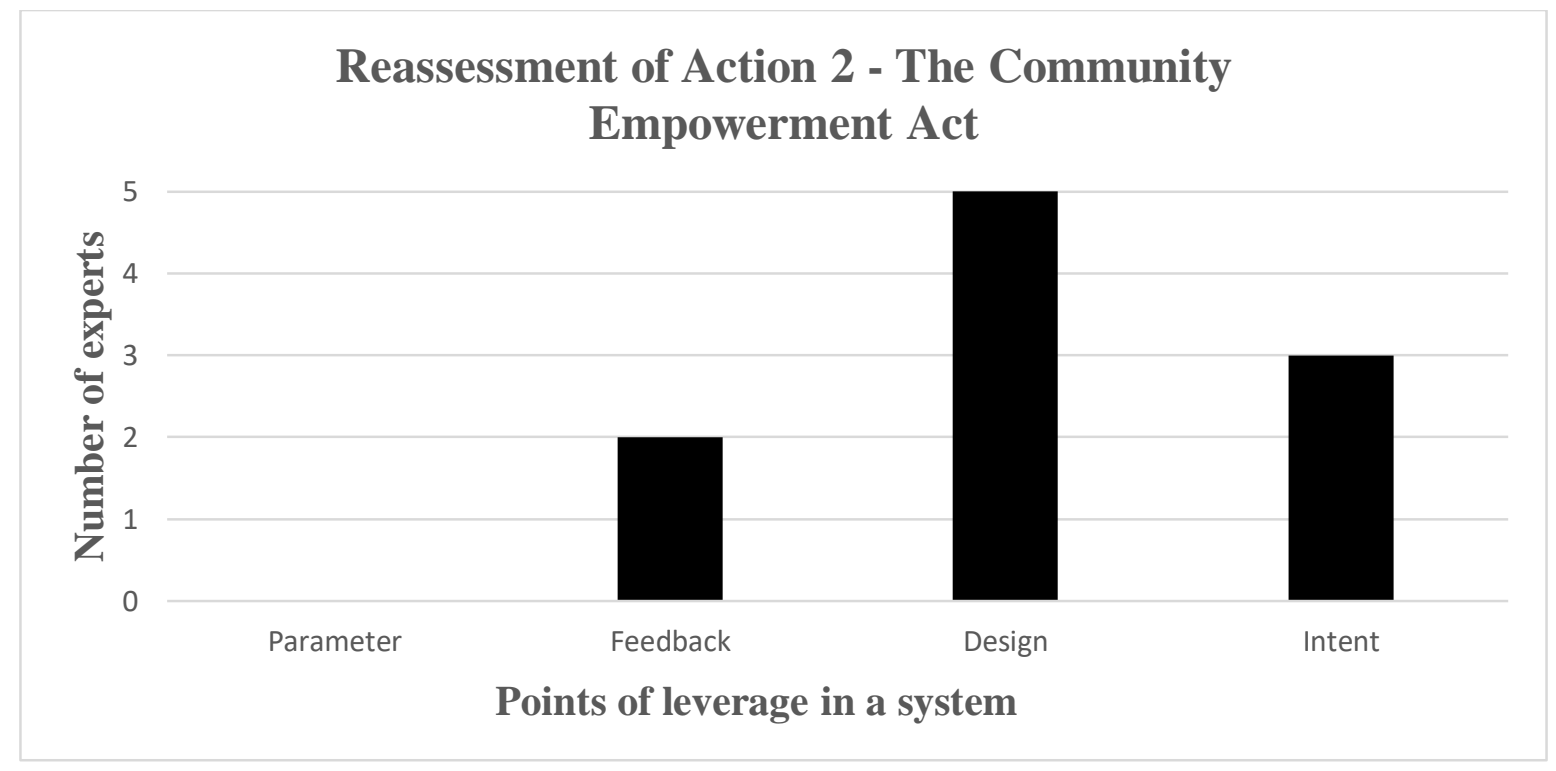

Figure 8 - The final assessment of action 2 after the third stage of the Delphi (compare against figure 4). Experts reached a unanimous consensus that action 2 targeted the "design" leverage point, and a near unanimous consensus that it targeted the "intent" leverage point.

However, when faced with the same choice of altering their assessment concerning Action 3 to reach unanimous consensus, Academic (2) opted to stay with their original assessment: 
"I will keep my assessment of Action 3 the same. I do not fully agree that the establishment of LES created positive feedback loops; those loops already existed when support for community energy was originally provided by Community Energy Scotland. What did change... alongside the establishment of LES was a change to the rules/design of the support system for community energy" - Academic Expert (2).

This resulted in Action 3 being the only intervention in which the experts could not find a unanimous agreement. Majority consensuses were also reached in round two that Action 2 targeted the "intent" leverage point and that Action 3 targeted the "design" leverage point. However, in both cases the experts who disagreed chose to remain with their initial assessment, not giving any reasons why they did so.

\subsubsection{Analysis and discussion concerning stage three of the Delphi exercise}

The move towards consensus exhibited by Academic (2) serves to highlight the value of the Delphi study. Through group interactions and feedback from other experts, participants would be persuaded to change their opinion leading to a unanimous consensus on the most likely trend of niche progress along a CE trajectory.

However, just because the experts were taking part in an interactive discussion in a virtual panel, it does not mean they would change their opinions to reach consensus. Academic (2) had an opportunity to create unanimous agreement regarding Action 3, but chose not to do so. The public and third sector experts both had opportunities to create near or unanimous consensus regarding Actions 2 and 3. However, both also declined to do so. While it is unfortunate that a further consensus was not reached, this disagreement shows critical consideration of evidence by the participants.

\section{Discussion}

This section presents a discussion of the key points arising from a critical examination of the relevant literature and the Delphi exercise assessing the progress of community renewable energy in Scotland toward the direction of a circular economy.

\subsection{Exploring differences between "niche progress" and "niche trajectory"}

It is apparent from the results of this study that CRE in Scotland is making progress towards disrupting the current fossil-based energy regime. However, The comments made by the experts throughout the study, particularly at the end of round three, show that just because a government's actions target a certain leverage point, this does not mean it would immediately 
achieve the desired change. The private sector expert's response to Action 2 (The Community Empowerment Act) highlights this point:

"At present the impacts of the empowerment act within community renewables is limited. The intent is there to empower communities... aiming to alter the rules towards the benefit of communities who often struggle to access suitable sites for community renewables development. In terms of feedback, greater access to land and property and the resulting empowerment may offer communities a means to further develop their local area, support wider community organisations and networks, and extrapolate the development of community renewables. In actuality this happens very rarely and in my experience is limited to community hall solar or biomass. Right to buy is also seen limited success in providing land to communities."- Private sector expert, round two

This quote shows that while there may be consensus regarding what leverage point has been targeted, this consensus does not show whether the actions have achieved change as desired. This means the level of consensus regarding the leverage points targeted by key actions is only able to show progress to a certain extent. In this study, the Scottish Government have been seen by the Delphi experts to be intervening across the four points of leverage studied, which suggests that the CRE niche is on a trajectory destined to disrupt the prevailing linear energy regime.

However, aligning niche activities to a CE-oriented trajectory does not show at what speed the niche is travelling along the trajectory or how far along the trajectory it has progressed, because it does not assess whether the actions have worked as intended. Therefore, when discussing assessment of niche progress, a distinction should be made between "niche trajectory" and "niche development". The former concerns whether the niche is on the right course. This is achieved through policy interventions targeting appropriate points of leverage in a system and can effectively be assessed using the Delphi study detailed in this paper. The latter, however, relates to the extent to which these interventions have achieved their desired goal.

\subsection{Recommendations for future research}

There are two main limitations to the methodology that bear on the conceptual and empirical aspects of this study. One of these limitations relates to the virtual absence of studies applying the multi-level perspective (MLP) to road-map transition to circular economy (CE), not least in the context of Scotland. The characterisations of CE regimes deriving from multiple CE niche breakthroughs, and the CE objective to be achieved through the transformation of all existing socio-technical regimes, are grounded entirely in established systems and MLP theory. 
However, while the approach to conceptualise CE transition in terms of MLP theory is novel, experientially it poses a daunting challenge for the methodological rigour of the study as there are no solid benchmark studies on the assessment of progress made in developing niches within protected spaces. In the circumstances, the optimality of the method used in this study as an assessment framework to gauge progress in CE transition and the choice of trajectories to this end based on the Delphi process remains tentative.

A second limitation of the methodology is that the research was conducted without any financial provision to compensate experts for their participation in the Delphi panel. Their participation turned purely on good will, which could not be stretched indefinitely to warrant involvement of experts in the panel over an extended period. Offering compensation would have made it possible to recruit more experts to participate in multiple rounds of consultation. This would have added more rigour to the results of the study, as a value deriving from consensus between 10 or more experts is, according to the Delphi literature, more probable as a forecast than one deriving from consensus reached between five experts. Also, in the absence of financial compensation for the experts, the number of questions to be explored had to be limited, albeit without excluding key issues. Thus, only five government actions were included in the study. The inclusion of more would have given an even greater insight into the failure or success of government intervention in the CRE niche. Moreover, the decision to use only four leverage points, as opposed to breaking them down into their constituent 12 points, was aimed to ensure participants were not put off continuing participation in the panel. Using 12 leverage points would have produced a clearer road- map of transition to CE. However, it was judged that it would be too much to expect panellists to read and fully understand 12 individual leverage points and be able to apply them in their assessment. A strict timetable for completion also meant that the study was limited to only three rounds of consultation.

Future studies with greater resources at their disposal may have the opportunity to increase expert participation and the number of rounds used in the method without diminishing the likelihood of experts participating for the entirety of the study. Increasing the number of rounds in the study would provide a greater opportunity for reaching consensus if little agreement exists after the initial assessment stage. Additional rounds would also provide more opportunity for feedback and group interaction in the form of experts' comments on each other's views, thus bringing out more novel information and knowledge relevant to the issue under exploration. However, care must be taken not to have a never-ending series of rounds for the sake of trying to reach a consensus. 
A higher number of participants on the panel would also help to strengthen the statistical significance of the predictive value of the consensus achieved. A consensus reached between 20 or 30 experts regarding an assessment provides a much stronger prediction than one reached between five experts. Moreover, an assessment of 10 or 15 actions could potentially provide a much larger and more accurate snapshot of progress in a niche. However, as the number of actions being assessed increases, the feasibility of experts including detailed explanations of their assessments for each action decreases. The same is true for the number of expert panellists involved in the study - as the number increases, the feasibility of each participant reading the assessments of every individual panellist decreases. This is a balancing act which future research must consider.

Future studies would also do better using all 12 points of leverage as the assessment criteria. With the provision of financial compensation to ensure retention of panellists, a full description of each individual leverage point could be given to each expert, so that they can understand and apply the full criteria properly when assessing each action. The use of all 12 leverage points would give a significantly more robust assessment criterion, showing what leverage points have been targeted out of 12 as opposed to the use of only four as was done in this study.

Future research could also consider how best to establish niche development, as it is fundamental in gauging the extent of progress in disrupting prevailing fossil-based energy regimes. During the Delphi study, experts were not urged specifically to make comments on whether government interventions have achieved the desired change at their targeted leverage point. Therefore, the research has not shown the extent of "niche development" in the CRE niche, only that it is on the trajectory relevant to CE transition. While this is still a valuable result, it does not give the full picture of CRE progress in Scotland. Indeed, it is not the claim of this paper to have produced a method for assessing niche progress in disrupting a regime; rather the claim is for a method which can assess whether a niche is on the optimal trajectory towards disrupting a socio-technical regime.

In this respect, experts could be asked during the second round of the Delphi study to make comments specifically concerning the extent to which the government actions under assessment have succeeded in achieving the targeted change. This could elicit rich qualitative feedback from which the state of niche development could be interpreted. 


\section{Conclusion}

This paper proposed a new approach to look at the processes involved in achieving a full system transition to a circular economy. This contributes to the growing body of knowledge about circular economy as it provides what has arguably been lacking in the $\mathrm{CE}$ literature to date, including the conceptualisation of CE as accumulation of socio-technical regimes, all of which must be aligned with $\mathrm{CE}$ imperatives; and the realisation of these regimes through the emergence of CE orientated niches.

This way of conceptualising CE transition also enables the creation of a method to assess the progress a country makes in developing CE orientated niches. By operationalising Meadow's (1999) 12 points of leverage in a system as an assessment tool to measure transition progress, this paper has attempted to address a key issue which has yet to be resolved in the context of the wider sustainability and transition literature - i.e. how to robustly assess the extent of progress made in the course of transition to a new system. The ability to assess transition progress is vital because as the environmental degradation of Planet Earth becomes increasingly severe, the margin of error for achieving success with interventions becomes ever smaller. Therefore it is vital to know if the interventions being taken now are not enough to warrant system transition, and if so, where they are failing. While the empirical aspect of this study is limited to the assessment of only a small part of niche progress, it nevertheless represents a crucial first step.

The results of the case study, based on the opinion of experts with specialised knowledge about the CRE industry, have shown that the actions taken by the Scottish Government would enable the CRE niche to eventually disrupt the existing fossil-based energy regime. Furthermore, the study helped identify an important distinction when considering niche development moving forward - i.e. niche trajectory and niche progress. The former is concerned with whether the niche is on the right course towards disruption, and the latter with the extent to which the niche has developed along the CE trajectory.

The case study also helped verify the effectiveness of the methodology used. Despite the limitations regarding the number of experts involved, the number of consultation rounds implemented, and the number of leverage points used, the method used in this study has been successful in generating signs of consensus among experts regarding the trajectory of the CRE niche in Scotland. This Delphi template can now be applied to assess the trajectory of every $\mathrm{CE}$ orientated niche. Identifying the trajectory of every niche is a crucial first step in assessing 
the total progress made in transitioning to $\mathrm{CE}$. CE cannot be achieved without the transformation of every regime, and the transformation of every regime cannot be achieved unless each CE-orientated niche is on the relevant trajectory.

\section{References}

Abson, J, Fischer, J, Leventon, J, Newig, J, Shomerus, T, Vilsmaier, U, Wehrden, H, Abernethy, P, Ives, C, Jager, N, Lang, D, 2016, Leverage points for sustainability transformation, Royal Swedish Academy of Sciences, volume 46, pp30-39

Biermann, F, 2012, Planetary boundaries and earth system governance: Exploring the links, Ecological Economics, Volume 81, pp4-9

Doci, G, Vasileiadou, E, Petersen, A, 2015, Exploring the transition potential of renewable energy, Futures, Volume 66, pp85-95

Doci, G, Gotchev, B, 2016, When energy policy meets community: Rethinking risk perceptions of renewable energy in Germany and the Netherlands, Energy Research and Social Science, Volume 22, pp26-35

Ellen Macarthur Foundation, 2013, Towards the Circular Economy, Economic and Business rationale for an Accelerated Transition, Retrieved at https://www.ellenmacarthurfoundation.org/assets/downloads/publications/Ellen-MacArthurFoundation-Towards-the-Circular-Economy-vol.1.pdf

Energy Saving Trust, 2017, Community and locally owned renewable energy in Scotland, a report by the Energy Saving Trust for the Scottish Government, retrieved at http://www.energysavingtrust.org.uk/sites/default/files/Community\%20and\%20locally\%20owned\%2 Orenewable\%20energy\%20report_2017.pdf

Etzkowitz, H, 2003, Innovation in innovation: The Triple Helix of university-industry-government relations, Social Science Information, Volume 42 pp293-337

Gallego, D, Bueno, S, 2014, Exploring the application of the Delphi method as a forecasting tool in information systems and technologies research, Technology Analysis and Strategic Management, Volume 26, p987-999

Geissdorfer, M, Savaget, P. Bocken, P, Hultink, E ,2017, The Circular Economy- A new sustainability paradigm? Journal of Cleaner Production, Volume 143, p757-768

Geels, F, 2002, Technological transitions as evolutionary reconfiguration processes: a multi-level perspective and a case-study, Research Policy, Volume 31, p1257-1274

Geels, F, 2011, The multi-level perspective on sustainability transitions: Responses to seven criticisms, Environmental Innovations and Societal Transitions, Volume 1, p24-40

Geels, F, 2018, Disruption and low-carbon system transformation: Progress and new challenges in socio-technical transitions research and the Multi-Level Perspective, Energy research and Social Science, Volume 37, p224-231

Geels, F, Kern, F, Fuchs, G, Hinderer, N, Kingl, G, Mylan, J, Neukirch, M, Wassermann, S, 2016, The enactment of socio-technical transition pathways: A reformulated typology and a comparative 
multi-level analysis of German and UK low-carbon electricity transition (1990-2014), Research Policy, Volume 45, p896-913

Geels, F, 2010, Ontologies, socio-technical transitions (to sustainability), and the multi-level perspective, Research policy, Volume 39, pp495-510

Geng, Y, Doberstein, B, 2008, Developing the circular economy in China: challenges and opportunities for achieving "leapfrog development", International Journal of Sustainable Development, Volume 15, pp231-239

Gooyert, V, Rouwette, E, Kranenburg, H, Freeman, H, Breen, H, 2016, Sustainability transition dynamics: Towards overcoming policy resistance, Technological Forecasting and Social Change, volume 111, pp135-145

Haf, S, Parkhill, K, McDonald, M, Griffiths, G, 2018, Distributing power? Community energy projects' experiences of planning, policy and incumbents in the devolved nations of Scotland and Wales, Journal of Environmental Planning and Management, DOI: 10.1080/09640568.2018.1453490

Hake, J, Ficscher, W, Venghaus, S, Weckenbrock, C, 2015, The German Energiewende- History and Status quo, Energy, Volume 92, p532-546

Hasson, F, Keeney, S, 2011, Enhancing rigour in the Delphi technique research, Technological Forecasting and Social Change, Volume 78, pp1695-1704

Hunt, L, Milne, S, 2013, The UK Energy System in 2050: Centralised or Localised? A Report on the Construction of the CLUES Scenarios, Retrieved from http://www.seec.surrey.ac.uk/research/SEERS/SEERS1.pdf

Iqbal, S, Pipin-Young, L, The Delphi method, 2009, Phycologists, Volume 22, p698-600

Jovane, F, Seliger, G, Stock, T, 2016, Competitive Sustainable Globalization General Considerations and Perspectives, 14th Global Conference on Sustainable Manufacturing, GCSM 3-5 October 2016, Stellenbosch, South Africa, Voulme 8, pp1-19

Kivama, P, Kern, F, 2016, Creative destruction or mere niche support? Innovation policy mixes for sustainability transitions, Research Policy, Volume 45, pp205-217

Krarup, M., Kiørboe, N. and Sramkova, H. 2015. Moving towards a circular economy: -successful Nordic business models. Nordic Council of Ministers.

Lachman, D, 2013, A survey and review of approaches to study transitions, Energy Policy, Volume 58 , pp. $269-276$

Lawhon, M, Murphy, J, 2011, Socio-technical regimes and sustainability transitions: Insights from political ecology, Progress in Human Geography, Volume 36, p354-378

Lazarevic, D, Valve, H, 2017, Narrating expectations for the Circular Economy: Towards a common and contested European transition, Energy research and Social Science, volume 31, pp60-69

Li, L, Birmele, J, Schaich, H, Konold, W, 2013, Transitioning to community-owned renewable energy: Lessons from Germany, Procedia Environmental Sciences, Volume 17, p719-728

Lieder, M, Rashid, A, 2016, Towards circular economy implementation: A comprehensive review in context of manufacturing industry, Journal of Cleaner Production, Volume 115, pp36-51

Local Energy Scotland, 2016, Scottish Government Good practice principles for shared ownership of onshore renewable energy developments, retrieved at https://www.localenergy.scot/media/79714/Shared-Ownership-Good-Practice-Principles.pdf 
Loe, R, 1995, Exploring complex policy questions using the policy Delphi: A multi round, interactive survey method, Applied Geography, Volume 15, p53-68

Markard, J, Truffer, B, 2008, Technological innovation systems and the multi-level perspective: Towards an integrated framework, Research policy, Volume 37, p596-615

Meadows, D, 1999, Leverage points: Places to intervene in a system, Heartland: The sustainability Institute

Michelini, G, Moraes, R, Cunha, R, Costa, J, Ometto, R, 2017, From linear to circular economy: PSS conducting the transition, Procedia CIRP, Volume 64, pp2-6

Murphy, K, 2012, The social pillar of sustainable development: a literature review and framework for policy analysis, Sustainability: Science, Practice and Policy, Volume 8, pp15-29

Nolden, C, 2013, Governing community energy- feed-in tariffs and the development of community wind energy schemes in the United Kingdom and Germany, Energy Policy, Volume 63, p543-552

Nowack, M, Endrikat, J, Guenther, E, 2011, Review of Delphi-based scenario studies: Quality and design considerations, Technological Forecasting and Social Change, Volume 78, p1603-1615

Ocampo, L, Abisa, J, Ombe J, Escoto, M, 2018, Sustainable Ecotourism Indicator with fuzzy Delphi method- A Philippine perspectives, Ecological Indicators, Volume 93, p874-888

Pill, J, Socio-Economic Planning Sciences, Volume 5, p57-71

Rockström, Steffen, W, Noone, K, Persson, Stuart Chapin, A, Lambin, F, Lenton, T, Scheffer, M, Folke, C, Schellnhuber, H, Nykvist, B, de Wit, C, Hughes, T, van der Leeuw, S, Rodhe, H, Sörlin, S, Snyder, K, Costanza, R, Svedin, U, Falkenmark, M, Karlberg, L, Corell, R, Fabry, V, Hansen, J, Walker, B, Liverman, D, Richardson, K, Crutzen, P, Foley, J, 2009, A safe operating space for humanity, Nature, Volume 461, pp472-475

Rommel, J, Radtke, J, Jorck, G, Mey, F, Yildiz, O, 2016, Community Renewable energy at a crossroads: A think piece on degrowth, technology, and the democratization of the German energy system, Journal of Cleaner Production, Volume 197, pp1745-1753

Rowe, G, Wright, G, 2011, The Delphi technique: Past, present and future prospects- introduction to the special issue, Technological Forecasting and Social Change, Volume 78, p1487-1490

Sauvé, S., Bernard, S. and Sloan, P., 2016, Environmental sciences, sustainable development and circular economy: Alternative concepts for trans-disciplinary research. Environmental Development, $17, \mathrm{pp} .48-56$.

Scottish Government. 2016, Making Things Last: A Circular Economy Strategy for Scotland, retrieved at https://www.gov.scot/Resource/0049/00494471.pdf

Scottish Government, 2017, Energy in Scotland: Get the facts, Retrieved from https://www.gov.scot/Topics/Business-Industry/Energy/Facts

Scottish Government, 2014, Good practice principles for Community benefits from Onshore renewable Energy developments, Retrieved at http://wisepower-project.eu/wp-content/uploads/LocalEnergy-Good-Practice-Principles.pdf

Scottish Government, 2017, Scottish Energy Strategy: The future of energy in Scotland, Retrieved at https://www.gov.scot/Resource/0052/00529523.pdf

Scottish Parliament, 2017, SPICe Briefing: Energy, Retrieved at http://www.parliament.scot/ResearchBriefingsAndFactsheets/S5/SB 17-17 Energy.pdf 
Smith, A, Vob, J, 2010, Innovation studies and sustainability transitions: The allure of the multi-level perspective, Research Policy, Volume 39, p435-448

Stahel, W.R, 2010, The Performance Economy, Palgrave McMillan

Steffen, W ,Rockström, J, Richardson, K, Cornell, S, Fetzer, I, Bennett, E, Biggs, R, Carpenter, S, de Vries, W, de Wit, C, Folke, C, Gerten, D, Heine, J, Mace, G, Persson, L, Ramanathan, Reyers, B, Sörlin, 2015, Planetary boundaries: Guiding human development on a changing planet, Science, Volume 347, Retrieved at http://science.sciencemag.org/content/early/2015/01/14/science.1259855

Strauss, H, Zeigler, L, 1975, Delphi, political philosophy and the future, Futures, Volume 7, pp. 184196

Turnheim, B, Berkhout, F, Geels, F, Hof, A, McMeekin, A, Nykvist, B, Van Vuuren, D, 2015, Evaluating sustainability transitions pathways: Bridging analytical approaches to address governance challenges, Global Environmental Change, Volume 35, p239-253

Urbinati, A, Chiaroni, D, Chiesa, V, 2017, Towards a new taxonomy of circular economy business models, Journal of Cleaner Production, Volume 168, pp487-498

Van Bree, B, Vernong, G, Kramer, G, 2010, A multi-level perspective on the introduction of hydrogen and battery-electric vehicles, Technological Forecasting and Social Change, Volume 77, pp529-540

Viardot, E, 2016, The role of cooperatives in overcoming the barriers to adoption of renewable energy, Energy Policy, Volume 63, pp756-764

Von Gracht, H, 2012, Consensus measurement in Delphi studies review and implications for future quality assurance, Technological Forecasting and Social Change, Volume 79, pp1525-1536

Walrave, B, Talmar, M, Podoynitsyna, S, Romme, G, Verbong, G, 2017, A multi-level perspective on innovation ecosystems for path breaking innovation, Technological Forecasting and Social Change, Volume 117, pp111-122

Whicher, A, Harris, C, Beverly, K, Swiatek, P, 2018, Design for circular economy: Developing an action plan for Scotland, Journal of Cleaner Production, volume 172, pp3237-3248

\section{Contributors' Details}

Jack Finn: Jack Finn recently graduated with MSc in Sustainability and Environmental Studies from the Department of Civil and Environmental Engineering at the University of Strathclyde in Glasgow, UK. He is currently employed as a bid writer for Everwarm Ltd. He is also a graduate member of the Institute of Environmental Management and Assessment. Contact: Connemara, Stornvaar Road, Campbeltown, PA28 6SW, Email: jakf18@hotmail.co.uk

Jack Barrie: is currently working as a senior analyst at Zero Waste Scotland. He is also a PhD candidate at the University of Strathclyde in the Department of Civil and Environmental Engineering. His $\mathrm{PhD}$ research is on the role of innovation systems in the transition to a circular economy, and he has been working on this as a Schmidt-MacArthur Fellow with the Ellen MacArthur Foundation. He holds a First Class MEng Degree in Civil and Environmental Engineering from the University of Edinburgh and an MPhil with Distinction from the University of Cambridge. He has several years 
professional experience in the fields of sustainable water supply, international development, solar energy, the sharing economy and product innovation. Contact: University of Strathclyde, Civil and Environmental Engineering Department, Level 5, James Weir Building, Glasgow G1 1XJ. Email: 1

jack.barrie@zerowastescotland.org.uk

Elsa João is Senior Lecturer and Director of Postgraduate Studies and the course leader for the MSc courses in Sustainability in Environmental Studies, and Environmental Entrepreneurship. She has expertise in the areas of Strategic Environmental Assessment (SEA), Environmental Impact Assessment (EIA), enhancement of positive impacts, sustainability and the circular economy. Her current research focuses on how enhancement can improve project design and strategic planning, and how best to implement the circular economy. She was elected one of the directors of the prestigious International Association for Impact Assessment for the period 2014-2017. She is the leader of the innovative SME Carbon Clinic, run in collaboration with the Carbon Trust, where students carry out carbon audits for small and medium size organisations. Contact: University of Strathclyde, Department of Civil and Environmental Engineering, Level 5, James Weir Building, Glasgow G1 1XJ. Email: elsa.joao@strath.ac.uk.

Girma Zawdie is Senior Lecturer in science, technology and innovation management and policy and international development at the University of Strathclyde. He has several years of teaching and research experience. Areas of his current research interest include issues in triple helix innovation systems, circular economy and sustainability. Contact: University of Strathclyde, Civil and Environmental Engineering Department, Level 5, James Weir Building, Glasgow G1 1XJ. Email: g.zawdie@strath.ac.uk. 